\title{
Information Revelation in an Insider Trading Model with More Informed Traders
}

\author{
Leonard F.S. Wang ${ }^{1 *}$ \\ ${ }^{1}$ Wenlan School of Business, Zhongnan University of Economics and Law, Wuhan, China \\ Email: lfswang@gmail.com
}

\begin{abstract}
In this paper, we extend Jain and Mirman (2000, 2002), Daher and Mirman (2006, 2007), Wang et al. (2009) and Wang and Wang (2010) on modeling insider trading under Cournot duopoly competition, but focus on changes in the financial side by introducing more owners as insiders, all of whom possess the same inside information and can trade in the stock market. We find that in reality, the output of listed firm decreases but quantity produced by other firm increases, though total output becomes less. Market makers are less responsive to both signals from real and financial sides, but will set stock prices higher with zero signals. The manager and each owner will order fewer stocks in the financial side, but the total order flow still depends upon the realized values of inside information. As the number of insiders increases, the profits of the manager and each owner will decrease correspondingly, so does the variance of the observed inside information. If the number approaches infinity, then all insiders' profits will also reach zero, and at the same time, there is no variance for the inside information. That is to say, all inside information is revealed to the public so the stock market is perfectly efficient.
\end{abstract}

Keywords: Cournot duopoly, insider trading, correlated signals, stock price, kyle model.

\section{Introduction}

Insiders are individuals who hold proprietary knowledge about aspects of the firms they are associated with. They possess inside information that affects the profitability of the firms. In modern organization of corporations, we see the separation of owner and manager on control and management in one aspect, and from the financial aspect, we observe that the manager is delegated for making production decisions, and for maximizing the market value of the firm to serve the best interests of company shareholders who are the owners of the corporation (or the fund managers who are concerned with the interests of the investors). ${ }^{1}$ This scenario is consistent with the financial market operation of the real world, because the listed company usually has a large number of shareholders.

Since the highly publicized financial scandals of Enron and WorldCom cases, insider trading has become the emerging policy issue and modelling focuses on many academic fields, such as law, economics, finance, management, etc.; the debate concerns the public desire of implementing regulations and laws, which prohibit insider trading. In the real world, insiders may not be limited to the manager and owner of a listed company. They may also be managers and directors of the competing firms possessing other firms' relevant inside information.

On the normative aspect, factors that make insider trading undesirable are discussed in Manove (1989) and Leland (1992), and in particular, Dow and Rahi (2003) incorporated real and financial decisions but only focused on the question of fairness rather than the relationship of real and financial decisions. On the positive aspect, following Kyle (1985), Jain and Mirman (2000) modeled the financial and real sectors together in order to study the insider's decision-making process and how it affects the output in the real sector, stock price of the firm in the financial sector, and the information revealed to the public. Jain and Mirman (2002) constructed a Cournot competition in both real and financial sectors, while Daher and Mirman $(2006,2007)$ added a second insider trader in Cournot model (henceforth named the

\footnotetext{
${ }^{1}$ Noe (1997) and Hu and Noe (2001) considered managerial incentive that is provided by the corporation and how it affects insider trading and firm performance in different ways of modeling.
} 
Duo-Cournot model). In their modeling, the manager is responsible for making real-sector decisions, and the owner has the same inside information as the manager but no managerial responsibilities.

The different set-up of market structures is crucial to delineate the intertwined relationship between the two sectors. To view the real-world scenario of a celebrity criminal of insider trading and the profit "earning" of the owner over the manager, Wang et al. (2009) extend Jain and Mirman (2000, 2002) and Daher and Mirman $(2006,2007)$ by postulating that the financial market be Stackelberg rather than Cournot, and explore the effect of introducing Stackelberg competition on the equilibrium, in terms of both real and financial effects. It shows that the owner's profits will increase, and he enjoys his privilege and has more incentive to know more about the manager because his profits can be enlarged. Meanwhile, managers' profits may either decrease or increase depending on the exogenous parameters of the model. Wang and Wang (2010) allow competition mode to change in the real side of Cournot duopoly and when compared with Daher and Mirman (2006, 2007), show that when the listed company with insiders becomes the leader in the industry, the reaction functions of insiders will change as well as the parameters of the market, to signal from real and financial sides, but the amount traded by insiders remains the same; so does the degree of information revelation. In particular, for the information revealed to the public, the stock price reveals more information with the Stackelberg real-leader model than that of the Stackelberg financial-leader model. Daher et al. (2012) further highlight the effect of the competition structure in the financial market on information revelation.

In this paper, we focus on changes in the financial side but introduce more owners as insiders, all of whom possess the same inside information and can trade in the stock market. We find that in the real side, the output of listed firm decreases but the output produced by other firm increases, though total output becomes less. Market makers are less responsive to signals from both real and financial sides, but will set stock prices higher with zero signals. The manager and each owner will order fewer stocks in the financial side, but the total order flow still depends upon the realized values of inside information. As the number of insiders increases, the profits of the manager and each owner will decrease correspondingly, so does the variance of the observed inside information. If the number approaches infinity, then all insiders' profits will also reach zero, and at the same time, there is no variance for the inside information. That is to say, all inside information is revealed to the public so the stock market is perfectly efficient.

The paper is organized as follows. Section 2 presents assumptions of the basic model, describes behavior of all agents, while Section 3 provides a method of solving a unique linear equilibrium. Section 4 compares the results with the Duo-Cournot model. Section 5 has concluding remarks.

\section{The Model}

The economy consists of one real product and one financial asset. The market for the real product is Cournot duopoly, and each firm produces the real product at no cost. The inverse demand function facing this industry is stochastic and linear, i.e.

$$
q^{\prime}=\left(a-b Y^{\prime}\right) \tilde{z}, a, b>0 .
$$

The prior distribution of $\tilde{z}$ is normal with mean $\bar{z}$ (assumed to be positive) and variance $\sigma_{z}^{2} \cdot q^{\prime}$ is the price of the real product. $Y^{\prime}$ is the aggregate quantity produced, while $y_{1}^{\prime}$ and $y_{2}^{\prime}$ are the corresponding outputs of the two firms, we have $Y^{\prime}=y_{1}^{\prime}+y_{2}^{\prime}$. With regard to the financial sector, firm 2 is privately owned and privately financed, while firm 1 is publicly owned. In the financial market, the asset is the stock of firm 1, the value of the asset is the net profit of the firm per share. The stock of firm 1 is publicly traded in a competitive stock market.

Note that the variable $\tilde{z}$ is the key variable for our discussions, because it represents the inside information. Investors only know about its mean and variance, but insiders can know its realized value after gathering information and a period of observation.

The insiders, one manager and many shareholders (owner), are in firm 1 . They have the same private information about the financial asset, but the owner has no managerial responsibilities. Knowing the realization of $\tilde{z}$, many insiders trade in the stock market based on their inside information, and they are risk-neutral rational traders. At the same time, there are noise traders, standing for small public 
investors with no information on $\tilde{z}$. The aggregate noise trade is denoted by a random variable $\tilde{u}$, which is normally distributed with mean zero and variance $\sigma_{u}^{2}$.

With many insiders in Cournot duopoly model, there is no change in the real side of the two firms. But in the financial side, there are $n$ insiders trading in the stock market, including one manger and $n-1$ owners. Then the total order flow becomes

$$
\tilde{r}=x_{1}(\tilde{z})+x_{2}(\tilde{z})+x_{3}(\tilde{z})+\cdots+x_{n}(\tilde{z})+\tilde{u}=x(\tilde{z})+\tilde{u}
$$

The market makers observe two signals, a noisy signal from the real market, denoted by the random variable $\tilde{q}=\left(a-b Y^{\prime}\right)(\tilde{z}+\tilde{\varepsilon})$, where $\tilde{\varepsilon}$ is normally distributed with mean zero and variance $\sigma_{\varepsilon}^{2}$. We assume that $\tilde{z}, \tilde{u}$ and $\tilde{\varepsilon}$ are independent. The two signals, the real signal and the order flow signal, are used by the market makers to set the price $\tilde{p}=p(\tilde{q}, \tilde{r})$, based on the equilibrium price function, to clear the market. The insiders know only the value of $\tilde{z}$ and do not know the values of $\tilde{u}, \tilde{\varepsilon}, \tilde{r}, \tilde{z}+\tilde{\varepsilon}$, while market makers do not know the realization $z$ of $\tilde{z}$ but know its distribution; neither can they observe $x_{1}, x_{2}, \ldots, x_{n}, u$ or $\varepsilon$.

The target function for firm 2, the owner's target function is the net profits from producing products,

$$
v_{2}^{\prime}=\left(a-b Y^{\prime}\right) y_{2}^{\prime} \tilde{z}
$$

and he needs to decide the optimal quantity produced $y_{2}$ to gain the maximum profit, which can be shown as

for any level of output $y_{2}{ }^{0}$ produced by firm 2 .

$$
\left(a-b\left(y_{1}^{\prime}+y_{2}^{\prime}\right)\right) y_{2}^{\prime} \tilde{z} \geq\left(a-b\left(y_{1}^{\prime}+y_{2}^{0}\right)\right) y_{2}^{0} \tilde{z}
$$

For the manager of firm 1, there are two parts of profits,

$$
\Pi_{1}=\left(v^{\prime}-B^{\prime}-p\right) \tilde{x}_{1}+B^{\prime} \tilde{x}_{1}
$$

The value per share of the firm 1 is defined to be the net profit of the firm per share,

$$
v^{\prime}=\left(a-b Y^{\prime}\right) y_{1}^{\prime} \tilde{z}
$$

For owners of firm 1, their targets are to choose optimal orders of stock and gain a maximum expected profit. The target functions are

$$
\Pi_{i}^{\prime}=\left(v^{\prime}-B^{\prime}-p\right) \tilde{x}_{i}^{\prime}(\tilde{z}), \mathrm{i} \in[2, \mathrm{n}]
$$

For any insiders other than the manager, their best strategies are

$$
\begin{aligned}
& E\left[\left(\left(a-b\left(y_{1}^{\prime}+y_{2}^{\prime}\right)\right) y_{1}^{\prime} \tilde{z}-B^{\prime}-p\left(x_{1}^{\prime}(\tilde{z})+x_{2}{ }^{\prime}(\tilde{z})+x_{3}{ }^{\prime}(\tilde{z})+\cdots+x_{n}{ }^{\prime}(\tilde{z})+\tilde{u}\right)\right) x_{i}{ }^{\prime}(\tilde{z})\right] \geq \\
& E\left[\left(\left(a-b\left(y_{1}^{\prime}+y_{2}{ }^{\prime}\right)\right) y_{1}^{\prime} \tilde{z}-B^{\prime}-p\left(x_{1}^{\prime}(\tilde{z})+x_{2}{ }^{\prime}(\tilde{z})+x_{3}{ }^{\prime}(\tilde{z})+\cdots x_{i}^{0}(\tilde{z})+\cdots+x_{n}{ }^{\prime}(\tilde{z})+\tilde{u}\right)\right) x_{i}^{0}(\tilde{z})\right]
\end{aligned}
$$

for any alternative strategy $x_{i}^{0}(\tilde{z})$.

Following Jain and Mirman (2000), the design for such a managerial scheme is for an alignment of the interests of the owner and the manager. Without it, the second order condition with respect to the choice of output is not satisfied for all values of $z$. Moreover, for the violation values of $z$, the manager tends to incur infinite losses for the firm, thus leading a conflict between the firm and the manager. With such a compensation scheme, there exists a unique linear equilibrium as in the Kyle model. The interpretation of $B$ is that there are two parts for the manager's compensation mechanism: the first deals with compensation per share, just like the owner; and the second part shows the manager is rewarded a constant amount per share of the stock bought, and conversely, penalized the same amount per share of the stock sold. But as observed, the coefficient of these two elements are the same, therefore for the manager, the compensation scheme doesn't affect him, while for the owner, the value of firm 1 is reduced by $B^{\prime}$, i.e. $\tilde{v}=v^{\prime}-B^{\prime}$, the after-compensation value.

The manager of firm 1 needs to decide the optimal quantity produced and the best trading strategy $x_{1}^{\prime}(\tilde{z})$ in order to gain the maximum profit. The change is that in the financial side, there are many owners as insiders. The best strategy for the manager of firm 1 is

$$
\begin{aligned}
& \left.E\left[\left(\left(a-b\left(y_{1}^{\prime}+y_{2}^{\prime}\right)\right) y_{1}^{\prime} \tilde{z}-p\left(x_{1}^{\prime}(\tilde{z})+x_{2}{ }^{\prime}(\tilde{z})+x_{3}{ }^{\prime}(\tilde{z})+\cdots+x_{n}{ }^{\prime}(\tilde{z})+\tilde{u}\right)\right) x_{1}^{\prime}(\tilde{z})\right)\right] \\
& \geq E\left[\left(\left(a-b\left(y_{1}^{0}+y_{2}^{\prime}\right)\right) y_{1}^{0} \tilde{z}-p\left(x_{1}^{0}(\tilde{z})+x_{2}{ }^{\prime}(\tilde{z})+x_{3}{ }^{\prime}(\tilde{z})+\cdots+x_{n}{ }^{\prime}(\tilde{z})+\tilde{u}\right)\right) x_{1}^{0}(\tilde{z})\right]
\end{aligned}
$$

for any level of output $y_{1}^{0}$ produced by firm 1 and any alternative trading strategy $x_{1}^{0}(\tilde{z})$. 
Note that $B^{\prime}$ is used to guarantee the existence of the unique linear equilibrium. This is a game with incomplete information, since market makers only know the distribution of $\tilde{z}$. The pricing rule p $(.$, .) always satisfies $p(\tilde{q}, \tilde{r})=E[\tilde{v} \mid \tilde{q}, \tilde{r}]$, and the stock price is equal to the conditional expectation of the asset value given real product price and stock order flow information. In this case, an equilibrium is linear if there exist constants $\mu_{0}^{\prime}, \mu_{1}^{\prime}, \mu_{2}^{\prime}$ such that

$$
p(q, r)=\mu_{0}^{\prime}+\mu_{1}^{\prime} q+\mu_{2}^{\prime} r, \forall q, r .
$$

\section{Derivation of Equilibrium}

First, we derive the reaction function of the owner of firm 2 . The first order condition is

$$
y_{2}^{\prime}=\left(a-b y_{1}^{\prime}\right) / 2 b
$$

The manager of firm 1 chooses $y_{1}^{\prime}$ and $x_{1}^{\prime}(\tilde{z})$ to maximize expected profit

$$
G_{1}^{\prime}=E\left[\left(\left(a-b Y^{\prime}\right) y_{1}^{\prime} \tilde{z}-p\left(x_{1}^{\prime}(\tilde{z})+x_{2}^{\prime}(\tilde{z})+x_{3}^{\prime}(\tilde{z})+\cdots+x_{n}^{\prime}(\tilde{z})+\tilde{u}\right)\right) x_{1}^{\prime}(\tilde{z})\right]
$$

The first-order conditions are

$$
\begin{gathered}
x_{1}^{\prime}=\left[\left(a-b Y^{\prime}\right)\left(y_{1}^{\prime}-\mu_{1}^{\prime}\right) \tilde{z}-\mu_{0}^{\prime}-\mu_{2}^{\prime}\left(x_{2}^{\prime}(\tilde{z})+x_{3}^{\prime}(\tilde{z})+\cdots+x_{n}^{\prime}(\tilde{z})\right)\right] / 2 \mu_{2}^{\prime} \\
y_{1}^{\prime}=\left(a-b y_{2}^{\prime}+\mu_{1}^{\prime} b\right) / 2 b
\end{gathered}
$$

Combining (11) and (14), we have

$$
\left\{\begin{array}{l}
y_{1}^{\prime}=\left(a+2 b \mu_{1}^{\prime}\right) / 3 b \\
y_{2}^{\prime}=\left(a-b \mu_{1}^{\prime}\right) / 3 b
\end{array}\right.
$$

Here we can see that outputs of the two firms are not affected by the number of insiders.

The owner of firm 1 chooses the decision strategy $x_{i}^{\prime}(\tilde{z})$ to maximize expected profits,

$$
\begin{aligned}
& G_{i}^{\prime}=E\left[\left(\left(a-b Y^{\prime}\right) y_{1}^{\prime} \tilde{z}-B^{\prime}-p\left(x_{1}^{\prime}(\tilde{z})+x_{2}^{\prime}(\tilde{z})+x_{3}^{\prime}(\tilde{z})\right.\right.\right. \\
& \left.\left.\left.+\cdots x_{i}^{\prime}(\tilde{z})+\cdots+x_{n}^{\prime}(\tilde{z})+\tilde{u}\right)\right) x_{i}^{\prime}(\tilde{z})\right]
\end{aligned}
$$

From the first-order conditions, we can derive the owner's order as

$$
x_{i}^{\prime}(\tilde{z})=\left[\left(a-b Y^{\prime}\right)\left(y_{1}^{\prime}-\mu_{1}^{\prime}\right) \tilde{z}-\mu_{0}^{\prime}-B^{\prime}-\mu_{2}^{\prime}\left(\sum_{j=2, j \neq i}^{n} x_{j}^{\prime}(\tilde{z})\right)\right] / 2 \mu_{2}^{\prime}
$$

Summing the value $x_{i}^{\prime}(\tilde{z})$ from 2 to $\mathrm{n}$, we have

$$
\sum_{i=2}^{n} x_{i}^{\prime}(\tilde{z})=\frac{(n-1)\left[\left(a-b Y^{\prime}\right)\left(y_{1}^{\prime}-\mu_{1}^{\prime}\right) \tilde{z}-\mu_{2}^{\prime} x_{1}^{\prime}(\tilde{z})\right]}{n \mu_{2}^{\prime}}
$$

Substituting (18) into (17), the owners' reaction functions are

$$
x_{i}^{\prime}(\tilde{z})=\left[\left(a-b Y^{\prime}\right)\left(y_{1}^{\prime}-\mu_{1}^{\prime}\right) \tilde{z}-\mu_{0}^{\prime}-B^{\prime}-\mu_{2}^{\prime} x_{1}^{\prime}(\tilde{z})\right] / n \mu_{2}
$$

Then taking (18) into the manager's reaction function (13), we have the optimal trading strategy of the manager

$$
x_{1}^{\prime}(\tilde{z})=\left[\left(a-b Y^{\prime}\right)\left(y_{1}^{\prime}-\mu_{1}^{\prime}\right) \tilde{z}-\mu_{0}^{\prime}+(n-1) B^{\prime}\right] /(n+1) \mu_{2}
$$

Solving (19) and taking into (20), we have the owners' optimal trading strategies as

$$
x_{i}^{\prime}(\tilde{z})=\left[\left(a-b Y^{\prime}\right)\left(y_{1}^{\prime}-\mu_{1}^{\prime}\right) \tilde{z}-\mu_{0}^{\prime}-2 B^{\prime}\right] /(n+1) \mu_{2}^{\prime}
$$

We assume the existence of linearity of the stock price. The above strategies show that the trading level of insiders is still a linear function of $\tilde{z}$. The outputs are deterministic and a linear function of $\tilde{z}$, since they remain the same. Hence, both the total order flow signal $\tilde{r}$ and the real signal $\tilde{q}$ are normal random variables. Besides, the value of firm 1 is also a normal random variable, since it is also a linear function of $\tilde{z}$. Consequently, the stock price, setting expected profits to be zero, is linear.

We then solve the coefficients of the price function as shown in Appendix A, which are

$$
\mu_{0}^{\prime}=\bar{v}-\mu_{1}^{\prime} \bar{q}-\mu_{2}^{\prime} \bar{r}
$$




$$
\begin{aligned}
& \mu_{1}^{\prime}=a \sigma_{z}^{2} / b\left(3(n+1) \sigma_{\varepsilon}^{2}+\sigma_{z}^{2}\right)=a k^{\prime} / b \\
& \mu_{2}^{\prime}=a^{2} \sigma_{\varepsilon} \sqrt{3 n\left(1-k^{\prime}\right)^{3} k^{\prime}} / 9 \sqrt{n+1} b \sigma_{u}
\end{aligned}
$$

where $k^{\prime}=\sigma_{z}^{2} /\left(\sigma_{z}^{2}+3(n+1) \sigma_{\varepsilon}^{2}\right)$.

The second-order conditions for the manager are $\mu_{2}^{\prime}>0$, and $x_{1}^{\prime}(\tilde{z}) \tilde{z}>0$, while the second-order condition for the owner is $\mu_{2}^{\prime}>0$. From (24), we know $\mu_{2}^{\prime}>0$ is always satisfied. Substituting the outputs and trading orders of the insiders into (22), through derivation we have

$$
\mu_{0}^{\prime}=\left(a-b Y^{\prime}\right)\left(y_{1}^{\prime}-\mu_{1}^{\prime}\right) \tilde{z}-2 B^{\prime}
$$

Substituting (20) and (25) into the above condition of the manager, it then reduces to

$$
\left[b\left(y_{1}^{\prime}-\mu_{1}^{\prime}\right)^{2}(\tilde{z}-\bar{z})+(n+1) B^{\prime}\right] \tilde{z}>0
$$

In (26), there may exist some values of $\tilde{Z}$ for which the second-order condition is not satisfied.

Here, we present a necessary and sufficient condition for the existence of the linear equilibrium for all $\tilde{z}$.

Proposition 1. In insider trading model with many insiders, a linear equilibrium exists if and only if,

$$
\mu_{0}^{\prime}=(n-1) B^{\prime}=(n-1)\left(a-b Y^{\prime}\right)\left(y_{1}^{\prime}-\mu_{1}^{\prime}\right) \bar{z} /(n+1)
$$

Proof. We can prove this first for sufficiency part: if $\mu_{0}^{\prime}=(n-1) B^{\prime}$, the expression for $x_{1}^{\prime}(\tilde{z})$ becomes $\quad x_{1}^{\prime}(\tilde{z})=\left(a-b Y^{\prime}\right)\left(y_{1}^{\prime}-\mu_{1}^{\prime}\right) \tilde{z} /(n+1) \mu_{2}^{\prime}=b y_{2}^{\prime 2} \tilde{z} /(n+1) \mu_{2}^{\prime}>0$. Thus, the second-order condition is satisfied. Hence, a linear equilibrium exists. Next, we prove the necessity. Since a linear equilibrium exists, the second-order condition is satisfied for all $\tilde{z}$. The second order condition has the form $c \tilde{z}^{2}+d \tilde{z}>0$. Here, $c=b\left(y_{1}^{\prime}-\mu_{1}^{\prime}\right)^{2}>0$ and $d=(n+1) B^{\prime}-b\left(y_{1}^{\prime}-\mu_{1}^{\prime}\right)^{2} \bar{z}$. Therefore, we must have $d=0$ to satisfy the second-order condition and thus the result is proved.

Proposition 2. In insider trading model with many insiders, a linear equilibrium exists. The equilibrium is unique and is characterized by

(i) $y_{1}^{\prime}=\left(a+2 b \mu_{1}^{\prime}\right) / 3 b$ and $y_{2}^{\prime}=\left(a-b \mu_{1}^{\prime}\right) / 3 b$,

(ii) $x_{1}^{\prime}(\tilde{z})=\left[\left(a-b Y^{\prime}\right)\left(y_{1}^{\prime}-\mu_{1}^{\prime}\right) \tilde{z}-\mu_{0}^{\prime}+(n-1) B^{\prime}\right] /(n+1) \mu_{2}^{\prime}$

and $x_{i}^{\prime}(\tilde{z})=\left[\left(a-b Y^{\prime}\right)\left(y_{1}^{\prime}-\mu_{1}^{\prime}\right) \tilde{z}-\mu_{0}^{\prime}-2 B^{\prime}\right] /(n+1) \mu_{2}^{\prime}$,

(iii) $p(\tilde{q}, \tilde{r})=\mu_{0}^{\prime}+\mu_{1}^{\prime} \tilde{q}+\mu_{2}^{\prime} \tilde{r}$,

(iv) $\mu_{0}^{\prime}=(n-1) B^{\prime}=(n-1)\left(a-b Y^{\prime}\right)\left(y_{1}^{\prime}-\mu_{1}^{\prime}\right) \bar{z} /(n+1)$,

(v) $\mu_{1}^{\prime}=a \sigma_{z}^{2} / b\left(3(n+1) \sigma_{\varepsilon}^{2}+\sigma_{z}^{2}\right)=a k^{\prime} / b$ and $\mu_{2}^{\prime}=a^{2} \sigma_{\varepsilon} \sqrt{3 n\left(1-k^{\prime}\right)^{3} k^{\prime}} / 9 \sqrt{n+1} b \sigma_{u}$,

where $k^{\prime}=\sigma_{z}^{2} /\left(\sigma_{z}^{2}+3(n+1) \sigma_{\varepsilon}^{2}\right)$ (see Appendix A), $\mu_{1}^{\prime} \in(0, a / b)$, and $\mu_{2}^{\prime}>0$

\section{Comparisons to Duo-Cournot Competition}

In the following comparisons, the variables without having " as the superscript denote the equilibrium outcome for the Duo-Cournot model. We would like to compare our results with Daher and Mirman's Duo-Cournot model in both real and financial sides.

\subsection{Stock Market Parameters and Outputs of Two Firms}

Lemma 1. The financial effects of insider trading model with many insiders, as compared to the DuoCournot model are as follows:

(i) $\mu_{0}^{\prime}>\mu_{0}, \mu_{1}^{\prime}<\mu_{1}, \mu_{2}^{\prime}<\mu_{2}$,

(ii) $y_{1}^{\prime}<y_{1}, y_{2}^{\prime}>y_{2}, Y^{\prime}<Y$,

(iii) $B^{\prime}<B$ 


\section{Proof.}

(i) By substituting $\mu_{1}^{\prime}, Y^{\prime}, y_{1}^{\prime}$ into proposition 2, we have $\mu_{0}^{\prime}=\left(n^{2}-1\right) a^{2} \sigma_{\varepsilon}^{4} \bar{z} / b\left(\sigma_{z}^{2}+3(n+1) \sigma_{\varepsilon}^{2}\right)^{2}$. Since $\mu_{0}=3 a^{2} \sigma_{\varepsilon}^{4} \bar{z} / b\left(\sigma_{z}^{2}+9 \sigma_{\varepsilon}^{2}\right)^{2}$, we know $\mu_{0}^{\prime}>\mu_{0}$ if $n>2$. From $\mu_{1}^{\prime}=a \sigma_{z}^{2} / b\left(3(n+1) \sigma_{\varepsilon}^{2}+\sigma_{z}^{2}\right)=a k^{\prime} / b$, we know that the value decreases as the number of insiders increases. And it is the same case with the relationship between $\mu_{2}^{\prime}$ and $\mu_{2}$.

(ii) From proposition 2, we know that outputs relationships just depend upon the relations between the parameters of market makers. Since from (i) we have $\mu_{1}^{\prime}<\mu_{1}$, thus $y_{1}^{\prime}=\left(a+2 b \mu_{1}^{\prime}\right) / 3 b$ and $Y^{\prime}=\left(2 a+b \mu_{1}^{\prime}\right) / 3 b$ follow the same pattern since they have a positive relationship with $\mu_{1}^{\prime}$, while $y_{2}^{\prime}=\left(a-b \mu_{1}^{\prime}\right) / 3 b$ appears to be the opposite pattern because $y_{2}^{\prime}$ and $\mu_{1}^{\prime}$ have a negative relationship.

(iii) As $B^{\prime}=\left(a-b Y^{\prime}\right)\left(y_{1}^{\prime}-\mu_{1}^{\prime}\right) \bar{z} /(n+1)$ decreases as $\mathrm{n}$ increases, we can easily obtain the outcome.

With the inclusion of more informed traders, the competition in the financial sector becomes intensified. In order to satisfy the zero expected profits, the market makers set different $\mu_{0}^{\prime}$. The first item of Lemma 1 shows that $\mu_{0}^{\prime}$, the intercept coefficient of the stock price, is increasing with more informed traders. From Eq. (A-1) and Eq. (A-2) in Appendix A, the increasing number of insiders increases the variance of the total order flow signal, $\sigma_{r}^{\prime 2}$, the covariance of the real signal and the total order flow, $\sigma_{q r}{ }^{\prime}$, as well as the covariance of the firm's value per share and the total order flow, $\sigma_{v r}{ }^{\prime}$. It turns out that the responses of market makers to these two signals both become less in this model.

The second item indicates output changes of the real sector affected by the response of market makers to the real signal. Although the output of firm 2 increases, the total output declines, due to output decrease of firm 1 .

Next, the owner will delegate less as the number of insiders increases. As shown in Proposition 1, to guarantee the existence of a linear equilibrium, the competition among $\mathrm{n}$ informed traders in the financial sector requires that the compensation scheme of the manager (which is positive) has the value $\mu_{0}^{\prime} /(n-1)$. We find that $B^{\prime}$ decreases with more informed traders.

\subsection{Amount of Insiders' Order Flow}

Lemma 2. In insider trading model with many insiders, comparisons of the insiders' level of trading, as well as the total order flow to those in Duo-Cournot model, yield:

(i) $x_{1}^{\prime}(\tilde{z})<x_{1}(\tilde{z})$

(ii) $x_{i}^{\prime}(\tilde{z})<x_{2}(\tilde{z})$

(iii) There exists a $z^{+} \in \mathbb{R}^{+}$such that $\left\{\begin{array}{l}x^{\prime}(\tilde{z})>x(\tilde{z}), \text { if } \tilde{z} \in\left(z^{+}, \infty\right), \\ x^{\prime}(\tilde{z})<x(\tilde{z}), \text { otherwise. }\end{array}\right.$

Proof.

(i) By substituting $y_{1}^{\prime}, y_{2}^{\prime}, \mu_{0}^{\prime}, \mu_{1}^{\prime}, \mu_{2}^{\prime}$ into $x_{1}^{\prime}(\tilde{z})$, we have $x_{1}^{\prime}=\sigma_{u} \tilde{z} / \sqrt{n} \sigma_{z}$, and since $x_{1}=\sqrt{2} \sigma_{u} \tilde{z} / 2 \sigma_{z}$, obviously we can obtain $x_{1}^{\prime}(\tilde{z})<x_{1}(\tilde{z})$ when $n>2$.

(ii) By substituting $y_{1}^{\prime}, y_{2}^{\prime}, \mu_{0}^{\prime}, \mu_{1}^{\prime}, \mu_{2}^{\prime}$ into $x_{i}^{\prime}(\tilde{z})$, we can get the trading order of the owners as $x_{i}^{\prime}=\sigma_{u}(\tilde{z}-\bar{z}) / \sqrt{n} \sigma_{z}$; while in the Duo-Cournot model we know $x_{2}(\tilde{z})=\sqrt{2} \sigma_{u}(\tilde{z}-\bar{z}) / 2 \sigma_{z}$. Thus, we can easily get the result.

(iii) Substituting $y_{1}^{\prime}, y_{2}^{\prime}, \mu_{0}^{\prime}, \mu_{1}^{\prime}, \mu_{2}^{\prime}$ into $x_{1}^{\prime}(\tilde{z})$, we have

$x^{\prime}(\tilde{z})=x_{1}^{\prime}(\tilde{z})+x_{2}^{\prime}(\tilde{z})+x_{3}^{\prime}(\tilde{z})+\cdots+x_{n}^{\prime}(\tilde{z})=\sigma_{u}(n \tilde{z}-(n-1) \bar{z}) / \sqrt{n} \sigma_{z}$. 
Comparing with $x(\tilde{z})=x_{1}(\tilde{z})+x_{2}(\tilde{z})=\sqrt{2} \sigma_{u} \tilde{z} / \sigma_{z}-\sqrt{2} \sigma_{u} \bar{z} / 2 \sigma_{z}$, we can know through calculation that if $\tilde{z}>(1+1 / \sqrt{2 n}) \bar{z}$ then $x^{\prime}(\tilde{z})>x(\tilde{z})$, and vice versa.

Lemma 2 shows that with an increasing number of informed traders in the financial sector, each trader's order decreases, while the level of total order depends on $\tilde{z}$. For the manager and owners of firm 1, the value of inside information decreases (will be proved in 4.3 and 4.4), as it is held by more and more people. Therefore, the inside trading is relatively declining. Only if $\tilde{z}$ is sufficiently large, will the total order increase.

\subsection{Manager's Profits}

We calculate the profits of the manager by substituting $y_{1}^{\prime}, y_{2}^{\prime}, x_{1}^{\prime}, x_{2}^{\prime}, \cdots x_{i}^{\prime}, \cdots x_{n}^{\prime}, \mu_{0}^{\prime}, \mu_{1}^{\prime}, \mu_{2}^{\prime}$ into equation (12) and obtain

$$
G_{1}^{\prime}=(n+1) a^{2} \sigma_{\varepsilon}^{4} \sigma_{u} \tilde{z}^{2} / b \sqrt{n} \sigma_{z}\left(\sigma_{z}^{2}+3(n+1) \sigma_{\varepsilon}^{2}\right)^{2} .
$$

Proposition 3. The expected profits of the manager will be reduced gradually as the number of owner increases.

Proof. Computing the first derivative of $G_{1}^{\prime}=(n+1) a^{2} \sigma_{\varepsilon}^{4} \sigma_{u} \tilde{z}^{2} / b \sqrt{n} \sigma_{z}\left(\sigma_{z}^{2}+3(n+1) \sigma_{\varepsilon}^{2}\right)^{2}$, we have $\partial G_{1}^{\prime} / \partial n=\left(\sigma_{z}^{2}(n-1)-3 \sigma_{\varepsilon}^{2}\left(3 n^{2}+4 n+1\right)\right) / 2 n^{3 / 2}\left(\sigma_{z}^{2}+3 \sigma_{\varepsilon}^{2}(n+1)\right)^{3}$. And there are two roots when the first derivative equals zero, i.e. $n_{1}=\left(-12 \sigma_{\varepsilon}^{2}+\sigma_{z}^{2}-\sqrt{36 \sigma_{\varepsilon}^{4}-60 \sigma_{\varepsilon}^{2} \sigma_{z}^{2}+\sigma_{z}^{4}}\right) / 18 \sigma_{\varepsilon}^{2} \quad$ and $n_{2}=\left(-12 \sigma_{\varepsilon}^{2}+\sigma_{z}^{2}+\sqrt{36 \sigma_{\varepsilon}^{4}-60 \sigma_{\varepsilon}^{2} \sigma_{z}^{2}+\sigma_{z}^{4}}\right) / 18 \sigma_{\varepsilon}^{2}$. We find that the larger root $n_{2}$ is smaller than 1 and if $n=1, \partial G_{1}^{\prime} / \partial n<0$, therefore, we draw the conclusion that for $n>1$, the first derivative is always negative, thus the value of $G_{1}^{\prime}$ will always decrease as the number of insiders $n$ increases.

\subsection{Owner's Profits}

Comparing the owner's expected profits of our model with the owner's profits in the Duo-Cournot model, we can show that the owner's profits are always smaller in our model.

In order to interpret the results, we can calculate the owner's profits by substituting $y_{1}^{\prime}, y_{2}^{\prime}, x_{1}^{\prime}, x_{2}^{\prime}, \cdots x_{i}^{\prime}, \cdots x_{n}^{\prime}, \mu_{0}^{\prime}, \mu_{1}^{\prime}, \mu_{2}^{\prime}$ into (16), and obtain

$$
G_{i}^{\prime}=(n+1) a^{2} \sigma_{\varepsilon}^{4} \sigma_{u}(\tilde{z}-\bar{z})^{2} / b \sqrt{n} \sigma_{z}\left(\sigma_{z}^{2}+3(n+1) \sigma_{\varepsilon}^{2}\right)^{2}
$$

Proposition 4. The expected profits of each owner will be reduced gradually as the number of owner increases.

Proof. Similar to the proof of proposition 3, thus omitted here.

The above two propositions indicate that the insiders' profits definitely decrease when the number of owners increases, which appears true to common sense. When more people rush in and divide the cake, each of them can only get a smaller piece.

\subsection{Information Revelation}

The measure of information is presented by the conditional variance of $\tilde{z}$ given the information of the market makers, which can be written as $\operatorname{Var}[\tilde{z} \mid \tilde{q}, \tilde{r}]$. After some calculation and substitution (see Appendix B), we have

$$
\operatorname{Var}[\tilde{z} \mid \tilde{q}, \tilde{r}]=\sigma_{\varepsilon}^{2} \sigma_{z}^{2} /\left(\sigma_{z}^{2}+(n+1) \sigma_{\varepsilon}^{2}\right)
$$

Proposition 5. The stock price reveals more information as the number of owners increases.

Clearly, the variance of observed inside information becomes smaller as $n$ increases, thus narrowing the scope of information that cannot be observed by market makers. Therefore, more information is revealed. 


\section{$5 \quad$ Concluding Remarks}

In this paper, we introduced more owners as insiders of the listed firm into the Cournot duopoly model. All of the insiders possess the same inside information and trade in the stock market to gain profits. We find that, in the real side, the output of listed firm decreases but the output produced by private firm increases, though total output reduces. Market makers are less responsive to both signals from real and financial sides, but will set stock prices higher with zero signals. The manager and each of the owners will order less stock in the financial side, but the total order flow still depends upon the realized values of inside information.

As the number of insiders increases, the profits of the manager and each of the owners will decrease correspondingly; so does the variance of the observed inside information. If the number approaches infinity, then all insiders' profits will also reach zero, and at the same time, there is no variance for the inside information. Under such circumstances, all inside information is revealed to the public and stock market. And the financial market is perfectly efficient.

Compared with the result obtained in Wang et al. (2009), and Wang and Wang (2010), we could see the following differences. Though total order of insiders may increase or decrease depending on the realized values of inside information in both scenarios, market makers put more weight on signals from the financial side in the Stackelberg leader model, while less weight on financial side signals in the present model. It seems that market makers can well observe and identify different changes. When the only owner becomes the leader in the financial side, market makers pay more attention to financial signals. But when more and more owners (shareholders or the fund managers) rush in for profits, market makers just let them go and pay less attention to financial signals, but at the same time, owners themselves help market makers better observe and understand the inside information.

In future research, it would be useful to study a market in which insiders know about other firms' inside information and use this information to trade. Another direction of extension is to make the model dynamic and examine the effects of past and present inside information and their influence on insiders as well as the financial market.

\section{References}

1. Daher W, Karam, F., Mirman L (2012). Insider trading with different market structures. International Review of Economics \& Finance, 24:143-154.

2. Daher W, Mirman L (2006). Cournot duopoly and insider trading with two insiders. The Quarterly Review of Economics and Finance, 46:530-551.

3. Daher W, Mirman L (2007). Market structure and insider trading. International Review of Economics and Finance, 16:306-331.

4. Dow J, Rahi R (2003). Informed trading, investment and welfare. Journal of Business, 76:439-454.

5. Hu J, Noe T (2001). Insider trading and managerial incentives. Journal of Banking \& Finance, 25:681-716.

6. Graybill F (1961). An introduction to linear statistical models: volume I. McGraw Hill.

7. Jain N, Mirman L (2000). Real and financial effects of insider trading with correlated signals. Economic Theory, 16:333-353.

8. Jain N, Mirman L (2002). Effects of insider trading under different market structures. The Quarterly Review of Economics and Finance, 42:19-39.

9. Kyle A (1985). Continuous auctions and insider trading. Econometrica, 53:1315-1335.

10.Leland H (1992). Insider trading: should it be prohibited? Journal of Political Economy, 100:859-887.

11.Manove M (1989). The harm from insider trading and informed speculation. Quarterly Journal of Economics, 104:823-845.

12.Noe T (1997). Insider trading and the problem of corporate agency. Journal of Law, Economics \& Organization, 13:287-318.

13.Wang L. F.S, WangY-C (2010). Stackelberg real-leader in an insider trading model. Studies in Economics and Finance, 27(1):30-46.

14.Wang, L. F.S, Wang Y-C, Ren S (2009). Stackelberg financial-leader in insider trading model. International Review of Economics \& Finance, 18:123-131. 


\section{Appendix A}

Using Graybill (1961), Theorem 3.10, p. 63, and following similar calculations in the Duo-Cournot model, we can get

$$
\left\{\begin{array}{l}
\mu_{0}^{\prime}=\bar{v}^{\prime}-\mu_{1}^{\prime} \bar{q}^{\prime}-\mu_{2}^{\prime} \bar{r}^{\prime}, \\
\mu_{1}^{\prime}=\left(\sigma_{v q}^{\prime} \sigma_{r}^{\prime 2}-\sigma_{v r^{\prime}} \sigma_{q r}{ }^{\prime}\right) / D^{\prime}, \\
\mu_{2}^{\prime}=\left(\sigma_{v r}^{\prime} \sigma_{q}^{\prime 2}-\sigma_{v q}^{\prime} \sigma_{q r}^{\prime}\right) / D^{\prime},
\end{array}\right.
$$

and then using $\tilde{r}, \tilde{q}$ and $\tilde{v}$, we have

$$
\begin{aligned}
& \sigma_{v q}^{\prime}=\left(a-b Y^{\prime}\right)^{2} y_{1}^{\prime} \sigma_{z}^{2}, \\
& \sigma_{r}^{\prime 2}=n^{2}\left(a-b Y^{\prime}\right)^{2}\left(y_{1}^{\prime}-\mu_{1}^{\prime}\right)^{2} \sigma_{z}^{2} /(n+1)^{2} \mu_{2}^{\prime 2}+\sigma_{u}^{2}, \\
& \sigma_{v r}{ }^{\prime}=n\left(a-b Y^{\prime}\right)^{2}\left(y_{1}^{\prime}-\mu_{1}^{\prime}\right) y_{1}^{\prime} \sigma_{z}^{2} /(n+1) \mu_{2}^{\prime}, \\
& \sigma_{q r}{ }^{\prime}=n\left(a-b Y^{\prime}\right)^{2}\left(y_{1}^{\prime}-\mu_{1}^{\prime}\right) \sigma_{z}^{2} /(n+1) \mu_{2}^{\prime}, \\
& \sigma_{q}^{\prime 2}=\left(a-b Y^{\prime}\right)^{2}\left(\sigma_{z}^{2}+\sigma_{\varepsilon}^{2}\right) .
\end{aligned}
$$

By substituting (A-2) into (A-1), we can have the parameters expressed in the reaction functions we have already solved.

$$
\begin{aligned}
& \mu_{1}^{\prime}=\left(a-b Y^{\prime}\right)^{2} y_{1}^{\prime} \sigma_{z}^{2} \sigma_{u}^{2} / D^{\prime} \\
& \mu_{1}^{\prime}=\left(a-b Y^{\prime}\right)^{2} y_{1}^{\prime} \sigma_{z}^{2} \sigma_{u}^{2} / D^{\prime}
\end{aligned}
$$

Combining (A-3) and (A-4), we can get

$$
(n+1) \mu_{2}^{\prime 2}=n\left(a-b Y^{\prime}\right)^{2} \mu_{1}^{\prime}\left(y_{1}^{\prime}-\mu_{1}^{\prime}\right) \sigma_{\varepsilon}^{2} / \sigma_{u}^{2}
$$

Then we calculate the expression for $D^{\prime}$ and can obtain

$$
D^{\prime}=n^{2}\left(a-b Y^{\prime}\right)^{4}\left(y_{1}^{\prime}-\mu_{1}^{\prime}\right)^{2} \sigma_{\varepsilon}^{2} \sigma_{z}^{2} /(n+1)^{2} \mu_{2}^{\prime 2}+\left(a-b Y^{\prime}\right)^{2} \sigma_{u}^{2}\left(\sigma_{\varepsilon}^{2}+\sigma_{z}^{2}\right)
$$

Taking (A-6) into (A-4), we find

$$
(n+1)^{2} \mu_{2}^{\prime 2}\left(\sigma_{\varepsilon}^{2}+\sigma_{z}^{2}\right)=\sigma_{z}^{2}\left(y_{1}^{\prime}+2 \mu_{1}^{\prime}\right)
$$

Combining (A-5) and (A-7), we have $(n+1) \mu_{2}^{\prime 2}\left(\sigma_{\varepsilon}^{2}+\sigma_{z}^{2}\right)=\sigma_{z}^{2}\left(y_{1}^{\prime}+n \mu_{1}^{\prime}\right)$

Substituting (15) into the equation above, we obtain

$$
\mu_{1}^{\prime}=a \sigma_{z}^{2} / b\left(3(n+1) \sigma_{\varepsilon}^{2}+\sigma_{z}^{2}\right)
$$

Solving $\mu_{2}^{\prime}$, we substitute the above value into (A-5), and then taking the positive root, we get

$$
\mu_{2}^{\prime}=a^{2} \sigma_{\varepsilon} \sqrt{3 n\left(1-k^{\prime}\right)^{3} k^{\prime}} / 9 \sqrt{n+1} b \sigma_{u}
$$

where $k^{\prime}=\sigma_{z}^{2} /\left(\sigma_{z}^{2}+3(n+1) \sigma_{\varepsilon}^{2}\right)$.

\section{Appendix B}

To solve for $\operatorname{Var}[\tilde{z} \mid \tilde{q}, \tilde{r}]$, we use the theorem in Appendix A. Suppose $Y_{0}^{d}=\left(\begin{array}{c}Y_{1}^{d} \\ Y_{2}^{d}\end{array}\right), \quad Y_{1}^{d}=\tilde{z}$ and $Y_{2}^{d}=\left(\begin{array}{l}\tilde{q} \\ \tilde{r}\end{array}\right)$. Then $U_{1}^{d}=\bar{z}, U_{2}^{d}=\left(\begin{array}{l}\bar{q} \\ \bar{r}\end{array}\right)$ and $V^{d}=\left(\begin{array}{ccc}\sigma_{z}^{2} & \sigma_{z q}^{d} & \sigma_{z r}^{d} \\ \sigma_{z q}^{d} & \left(\sigma_{q}^{d}\right)^{2} & \sigma_{q r}^{d} \\ \sigma_{z r}^{d} & \sigma_{q r}^{d} & \left(\sigma_{r}^{d}\right)^{2}\end{array}\right)=\left(\begin{array}{cc}V_{11}{ }^{d} & V_{12}{ }^{d} \\ V_{21}{ }^{d} & V_{22}{ }^{d}\end{array}\right)$, where $V_{11}^{d}=\sigma_{z}^{2}, V_{12}{ }^{d}=\left(\begin{array}{ll}\sigma_{z q}^{d} & \sigma_{z r}^{d}\end{array}\right), \quad V_{21}^{d}=\left(\begin{array}{l}\sigma_{z q}^{d} \\ \sigma_{z r}^{d}\end{array}\right)$ and $V_{22}^{d}=\left(\begin{array}{cc}\left(\sigma_{q}^{d}\right)^{2} & \sigma_{q r}^{d} \\ \sigma_{q r}^{d} & \left(\sigma_{r}^{d}\right)^{2}\end{array}\right)$. 
Note that $\left(V_{22}{ }^{d}\right)^{-1}=\frac{1}{D^{d}}\left(\begin{array}{ll}\left(\sigma_{r}^{d}\right)^{2} & -\sigma_{q r}^{d} \\ -\sigma_{q r}^{d} & \left(\sigma_{q}^{d}\right)^{2}\end{array}\right)$, where $D^{d}$ is the determinant of $V_{22}{ }^{d}$, that is $D^{d}=\left(\sigma_{q}^{d}\right)^{2}\left(\sigma_{r}^{d}\right)^{2}-\left(\sigma_{q r}^{d}\right)^{2}$.

So we have the conditional variance of $\tilde{z}$ is

$\operatorname{Var}[\tilde{z} \mid \tilde{q}, \tilde{r}]=V_{11}{ }^{d}-V_{12}{ }^{d}\left(V_{22}{ }^{d}\right)^{-1} V_{21}{ }^{d}=\left(\sigma_{z}^{d}\right)^{2}-\left(\begin{array}{ll}\sigma_{z q}^{d} & \sigma_{z r}^{d}\end{array}\right) \frac{1}{D^{d}}\left(\begin{array}{cc}\left(\sigma_{r}^{d}\right)^{2} & -\sigma_{q r}^{d} \\ -\sigma_{q r}^{d} & \left(\sigma_{q}^{d}\right)^{2}\end{array}\right)\left(\begin{array}{l}\sigma_{z q}^{d} \\ \sigma_{z r}^{d}\end{array}\right)$

Substitute equations in (A-2) and $\sigma_{z q}^{d}=\left(a-b Y^{\prime \prime \prime}\right) \sigma_{z}^{2}$,

$\sigma_{z r}^{d}=n\left(a-b Y^{\prime}\right)\left(y_{1}^{\prime}-\mu_{1}^{\prime}\right) \sigma_{z}^{2} /(n+1) \mu_{2}^{\prime}$, as well as $y_{1}^{\prime}, y_{2}^{\prime}, x_{1}^{\prime}, x_{2}^{\prime}, \mu_{0}^{\prime}, \mu_{1}^{\prime}, \mu_{2}^{\prime}$, we can obtain $\operatorname{Var}[\tilde{z} \mid \tilde{q}, \tilde{r}]=\sigma_{\varepsilon}^{2} \sigma_{z}^{2} /\left(\sigma_{z}^{2}+(n+1) \sigma_{\varepsilon}^{2}\right)$ 